\title{
O ENSINO DA SOCIOLOGIA EM CURSOS SUPERIORES DE OUTRAS ÁREAS DE FORMAÇÃO A perspetiva de docentes e diretores
}

\author{
Catarina Egreja \\ Instituto Universitário de Lisboa (ISCTE-IUL), Centro de Investigação e Estudos de Sociologia \\ (CIES-IUL), Lisboa, Portugal
}

\begin{abstract}
Resumo O presente artigo pretende dar um contributo para a atualização do conhecimento sobre a presença da sociologia no ensino superior português - não enquanto área científica principal, mas sim na sua mobilização por outros cursos e áreas de formação. Após o levantamento de informação nos planos curriculares, procurou-se perceber de que forma a disciplina se enquadra no âmbito geral do curso e qual a sua utilidade, pelo que se entrevistaram alguns responsáveis (coordenador / docente da disciplina) em diferentes cursos / instituições. Em suma, o ensino da sociologia nestes contextos, apesar de ser valorizado, enfrenta vários obstáculos.
\end{abstract}

Palavras-chave: sociologia, ensino superior, multidisciplinaridade, ISCED.

Abstract The present article seeks to help update what we know about Sociology's place in Portuguese higher education - not as a primary academic field, but rather when mobilised by other courses and areas. After surveying the information in curricular plans, the author looks at how the discipline fits into the general framework of other courses and how useful people find it, with interviews of a number of senior staff (coordinators / teachers) from different courses and institutions. The outcome shows that although Sociology is valued in such contexts, it still faces various obstacles.

Keywords: Sociology, higher education, multidisciplinarity, ISCED.

Résumé Cet article apporte une contribution à l'actualisation des connaissances sur la présence de la Sociologie dans l'enseignement supérieur portugais - non en tant que discipline scientifique principale, mais dans sa mobilisation par d'autres filières de formation. Après le relevé d'informations dans les programmes d'études, l'article tâche de comprendre de quelle façon cette discipline s'inscrit dans le cadre général de la formation et quelle est son utilité. À cet effet, quelques responsables (directeurs / enseignants de la discipline) de différents établissements / formations ont été interrogés. En somme, bien que l'enseignement de la Sociologie soit valorisé dans ces contextes, il rencontre plusieurs obstacles.

Mots-clés: Sociologie, enseignement supérieur, multidisciplinarité, ISCED.

Resumen El presente artículo pretende dar una contribución para la actualización del conocimiento sobre la presencia de la Sociología en la enseñanza superior portuguesa, no como área científica principal sino en su incorporación en otros cursos y áreas de formación. Después del levantamiento de información en los planes curriculares se procuró entender de que forma la disciplina se encuadra en el ámbito general del curso y cuál es su utilidad, por lo que se entrevistaron a algunos responsables (coordinador/docente de la asignatura) en diferentes cursos/instituciones. En conclusión, la enseñanza de la Sociología en estos contextos, a pesar de ser valorada, enfrenta varios obstáculos.

Palabras clave: Sociología, enseñanza superior, multidisciplinariedad, ISCED 


\section{Introdução}

Nas últimas décadas, a sociologia tem vindo a ganhar dimensão, tanto ao nível do ensino superior como da investigação em Portugal. Este crescimento, acompanhado de uma maior notoriedade, verifica-se não só no seio das ciências sociais, mas também noutras áreas do conhecimento, potenciando a multidisciplinaridade na produção científica. No entanto, o olhar reflexivo da sociologia sobre esta realidade tem sido descurado.

O presente artigo pretende dar um contributo para a atualização do conhecimento nesta área, focando-se ao nível do ensino - não o ensino da sociologia como área científica principal, mas sim a sua mobilização por outros cursos e áreas no ensino superior. Qual a presença da sociologia no ensino superior português? Como é que esta é vista por docentes e coordenadores de curso? A pesquisa ${ }^{1}$ iniciou-se com o levantamento das licenciaturas e mestrados integrados que lecionam uma disciplina de sociologia no ensino superior português, excluindo os próprios cursos de sociologia, para permitir perceber quais as áreas mais e menos recetivas à integração desta disciplina na formação dos seus alunos e também que diferenças existem entre os vários subsistemas de ensino. Na fase seguinte da pesquisa, procurou-se perceber de que forma a sociologia se enquadra no âmbito geral do curso e qual a sua utilidade - tanto prevista como perceciona$\mathrm{da}-$, pelo que se entrevistaram alguns responsáveis (coordenadores e docentes da disciplina) em diferentes cursos / instituições. Apresentam-se aqui as principais conclusões da análise das entrevistas.

\section{A presença e o ensino da sociologia em cursos superiores de outras áreas de formação: um enquadramento}

A evolução e presença da sociologia em Portugal tem sido objeto de reflexão por parte de vários autores (Almeida, 1992; 2004; Costa, 1996; 2004; Machado, 1993; 2004; 2009; Nunes, 1988; Pinto, 2004). No entanto, as referências teóricas sobre o ensino da sociologia em cursos de outras áreas de formação são escassas (Almeida, 1992; Nunes, 1963; Resende e Vieira, 1993).

Alguns estudos debruçam-se sobre as particularidades e dificuldades do ensino da disciplina - sobretudo, nas áreas da economia / gestão (referências em Almeida, 1992; Esteves, 2004; Pinto, 1994) e da formação de professores (Cortesão, 1992; Esteves e Stoer, 1992; Vieira, 2004). Uma das principais questões abordadas é a dos "efeitos" da presença da sociologia nestes cursos, geralmente vistos como benéficos mas, por vezes, de alcance muito limitado (Almeida, 1992). Tanto Cortesão (1992) como, uma década mais tarde, Vieira

1 Trabalho desenvolvido no âmbito do projeto de investigação doutoral atualmente em curso no CIES / ISCTE-IUL, intitulado “O Papel da Sociologia em Contextos de Ensino e de Investigação Multidisciplinares", objeto de uma bolsa da FCT com a referência SFRH / BD / 84515 / 2012, e orientado pelo professor doutor António Firmino da Costa. 
(2004) concluem que a sociologia tem bastante importância na formação dos professores, sobretudo pelo seu contributo para o desempenho bem-sucedido das suas funções profissionais.

Outra abordagem ao ensino da sociologia fora do espaço sociológico é a identificação e observação de possíveis constrangimentos ou dificuldades sentidos pelos professores que a lecionam. Os autores referem o contacto único e pontual e a temporalidade reduzida da disciplina (Vieira, 2004); a necessidade acrescida de seleção e condensação de saberes (Vieira, 2004); o contacto com o pluralismo teórico característico da sociologia, por poder ser visto como algo de estranho e muitas vezes indutor de suspeitas quanto à sua cientificidade (Sebastião, 2004; Vieira, 2004); e, ainda, uma localização periférica ou secundária da sociologia nos cursos (Esteves, 2004).

Tais dificuldades constituem um desafio à relação pedagógica e levantam problemas de legitimação da presença da sociologia nos cursos (Pinto, 1994; Esteves, 2004). De acordo com Esteves (2004: 67), nestes casos, a estratégia a utilizar deve ser tornar força pedagógica a fraqueza curricular da sociologia, que poderá ser desenvolvida pelo estabelecimento de um programa explicitamente formulado numa lógica de afinidades eletivas com paradigmas que, transdisciplinares, são menosprezados ou totalmente esquecidos pelos paradigmas dominantes e excludentes das disciplinas centrais do curso. Por seu lado, Pinto (1994) dá especial importância ao desenvolvimento dos problemas técnico-metodológicos da pesquisa sobre situações concretas, com especial incidência na fase da recolha de informação. O autor refere que os fatores que influenciam as opções pedagógico-didáticas na cadeira são: a dinâmica de transformação dos sistemas de aspirações socioprofissionais e dos perfis da procura de saberes predominantes na população discente universitária; circunstancialismos vários ligados a imposições administrativas quanto a planos de curso, regimes de aulas, dimensão das equipas docentes e formação académica, pedagógica e profissional dos seus elementos; e, finalmente, o tipo de preparação obtida pelos estudantes no ensino secundário, bem como algumas tradições e rotinas instaladas na universidade em matéria de ritmos de lecionação e de avaliação de conhecimentos (Pinto, 1994: 49-50).

Encontramos também algumas referências às vantagens e desvantagens percebidas pelos alunos de outras áreas científicas na aprendizagem da sociologia. Sebastião (2004: 130) afirma que aprender sociologia não é apenas dominar um conjunto de conceitos ou técnicas, mas construir no aluno uma progressiva maturidade reflexiva, capaz de o levar a compreender a relação entre as particularidades da atividade científica em ciências sociais e a complexidade da vida social. Para Vieira (2004: 145), as três principais dificuldades de entendimento da sociologia por parte dos alunos em cursos de ciências exatas e naturais, são: o caráter pluriparadigmático das ciências sociais, em contraste com o sólido uniparadigmatismo que parece dominar a prática científica nas ciências exatas e naturais; a compreensão do sentido, ou seja, sobre o estatuto da subjetividade dos atores sujeitos do conhecimento, já que nas "suas" ciências não existem atores-sujeitos reflexivos; e por fim, a questão da validade dos resultados em ciências sociais e humanas, não tendencialmente universalista, como nas "ciências duras", mas 
fundamentada numa "epistemologia dos domínios de validade" de alcance mais limitado.

Realizou-se um levantamento ${ }^{2}$ dos cursos do $1 .^{\circ}$ ciclo $^{3}$ do ensino superior português (anos letivos de 2012/2013 e 2013/2014) que facultam uma ou mais unidades curriculares na área da sociologia, semelhante ao efetuado há duas décadas por Resende e Vieira (1993). Foi então criada uma listagem que inclui informação sobre a instituição de ensino superior, o nome do curso e o grau correspondente, o nome $\mathrm{da}(\mathrm{s})$ disciplina(s) lecionada(s), o tipo de obrigatoriedade de frequência de cada disciplina e o ano curricular em que é lecionada. Foram contabilizadas 106 instituições, entre universidades, academias, escolas e institutos superiores, que têm pelo menos um curso (licenciatura ou mestrado integrado) em que a sociologia é lecionada (estando excluídos os cursos específicos desta área): 14 no sistema público universitário, 22 no sistema público politécnico, 3 no regime militar e policial, 28 no sistema privado universitário e, por fim, 39 no sistema privado politécnico. Foram contabilizados 655 cursos com as especificações indicadas, assim distribuídos: 170 no ensino público universitário, 216 no ensino público politécnico, 8 no ensino militar e policial, 165 no ensino privado universitário e, por fim, 96 no ensino privado politécnico.

Em seguida, procedeu-se à caracterização dos cursos por áreas científicas, com recurso à classificação mais agregada de domínios da educação e formação utilizada na ISCED (2013), ${ }^{4}$ concluindo-se que a maior parte se encontra na área de saúde e bem-estar (148 cursos, 22,6\% do total). Com valores próximos, surgem as áreas de gestão, administração e direito (111 cursos, 17,0\% do total); ciências sociais, jornalismo e informação (107 cursos, $16,3 \%$ do total); e artes e humanidades ( 99 cursos, 15,1\% do total). A meio, encontramos cursos das áreas de serviços (63 cursos, 9,6\% do total), engenharia, manufatura e construção (56 cursos, 8,6\% do total) e educação ( 44 cursos, $6,7 \%$ do total). Por fim, com muito poucos casos, temos as áreas de ciências naturais, matemática e estatística ( 13 cursos, 2,0\% do total); tecnologias da informação e da comunicação (10 cursos, 1,5\% do total); e agricultura, silvicultura, pescas e veterinária ( 4 cursos, $0,6 \%$ do total).

\section{Considerações metodológicas}

A informação recolhida sobre a presença da sociologia no ensino superior permitiu fazer a seleção dos cursos / instituições para realização das entrevistas de forma

2 Apresenta-se aqui um resumo da informação mais relevante recolhida na fase anterior da pesquisa de doutoramento; a versão completa pode ser consultada em Egreja (2014), se bem que alguns dados tenham sido revistos e atualizados entretanto.

3 Analisaram-se todas as licenciaturas e mestrados integrados. Sublinhe-se que, apesar de tudo, ficam de fora desta análise todos os outros mestrados, pós-graduações, doutoramentos e outros tipos de formações que podem existir em instituições de ensino superior, muitos deles certamente também com valências na área da sociologia.

4 International Standard Classification of Education, adotada pela UNESCO. O documento pode ser consultado em: http://www.uis.unesco.org/Education/Documents/isced-fields-of-education-training-2013.pdf 
Quadro 1 Caracterização dos entrevistados por área ISCED e sistema(s) de ensino

\begin{tabular}{|c|c|c|c|c|c|c|}
\hline \multirow[b]{2}{*}{ Área ISCED do curso } & \multicolumn{4}{|c|}{ Sistema de ensino } & \multirow[b]{2}{*}{ Docente } & \multirow[b]{2}{*}{ Diretor } \\
\hline & $\begin{array}{l}\text { Universitário } \\
\text { público }\end{array}$ & $\begin{array}{l}\text { Politécnico } \\
\text { público }\end{array}$ & $\begin{array}{l}\text { Universitário } \\
\text { privado }\end{array}$ & $\begin{array}{l}\text { Politécnico } \\
\text { privado }\end{array}$ & & \\
\hline Saúde e bem-estar (SBE) & & $\begin{array}{l}x \\
x\end{array}$ & $x$ & $x$ & $\begin{array}{c}\text { A } \\
\text { B1, B2 } \\
\text { C } \\
\text { D }\end{array}$ & $\begin{array}{l}A \\
B \\
C \\
D\end{array}$ \\
\hline $\begin{array}{l}\text { Gestão, administração } \\
\text { e direito (GAD) }\end{array}$ & $\mathrm{x}$ & & $x$ & $x$ & $\begin{array}{l}E \\
- \\
G\end{array}$ & $\begin{array}{l}E \\
F \\
-\end{array}$ \\
\hline $\begin{array}{l}\text { Ciências sociais, } \\
\text { jornalismo e informação } \\
\text { (CSJI) }\end{array}$ & & $x$ & $x$ & & $\begin{array}{c}\mathrm{H} 1, \mathrm{H} 2 \\
\mathrm{I}\end{array}$ & $\begin{array}{l}\mathrm{H} \\
-\end{array}$ \\
\hline Artes e humanidades $(\mathrm{AH})$ & $\begin{array}{l}x \\
x\end{array}$ & $x$ & & & $\begin{array}{l}- \\
\mathrm{K} \\
\mathrm{L}\end{array}$ & $\begin{array}{l}\mathrm{J} \\
\mathrm{K} \\
\mathrm{L}\end{array}$ \\
\hline Serviços (S) & & $x$ & & & M & M \\
\hline Educação (E) & $x$ & & & & $\mathrm{~N} 1, \mathrm{~N} 2, \mathrm{~N} 3$ & $\mathrm{~N}$ \\
\hline $\begin{array}{l}\text { Engenharia, manufatura } \\
\text { e construção (EMC) }\end{array}$ & $\begin{array}{l}x \\
x\end{array}$ & & & & $\begin{array}{l}\mathrm{O} \\
\mathrm{P}\end{array}$ & - \\
\hline Outras áreas $(\mathrm{OA})$ & $x$ & & & & Q & Q \\
\hline
\end{tabular}

informada, contemplando as diferentes áreas ISCED e tendo em atenção a sua distribuição por subsistemas de ensino. Em primeiro lugar, optou-se por eliminar o sistema de ensino superior militar e policial, não só pela sua especificidade, como pelo reduzido número de casos que apresenta; em segundo lugar, tomou-se a decisão de agregar as áreas de ciências naturais, matemática e estatística, tecnologias da informação e da comunicação, e agricultura, silvicultura, pescas e veterinária numa nova classificação - "outras áreas", devido ao reduzido número de casos em cada uma das categorias. Por último, de forma a avançar para o trabalho de campo, calculou-se o número ideal de cursos por área e sistema de ensino com vista a respeitar a proporção real anteriormente calculada (Egreja, 2014), mas sem preocupações de representatividade.

O guião de entrevista utilizado foi construído de raiz, debruçando-se sobre os seguintes tópicos: caracterização pessoal e institucional; presença e avaliação da sociologia no curso; considerações sobre o ensino da disciplina; expectativas de competências adquiridas e de contributo para a inserção profissional e futuras funções dos alunos; e perspetivas sobre os motivos de escolha da disciplina e aspetos mais e menos valorizados pelos alunos. À margem das questões do guião, outros temas de interesse foram abordados pelos entrevistados, uma vez que as entrevistas seguiram um método semidiretivo (Quivy e Campenhoudt, 1998).

O trabalho de campo decorreu de setembro de 2014 a junho de 2015, e foram realizadas 32 entrevistas em 17 cursos (em instituições de norte a sul do país), cujas características podem ser consultadas no quadro 1. Em alguns casos, não foi 
possível realizar entrevistas ao par docente / diretor no mesmo curso, enquanto noutros se entrevistou mais que um docente, pelo facto de haver oferta de mais que uma disciplina da área da sociologia.

\section{Caracterização dos entrevistados}

Os docentes que foram entrevistados têm entre 34 e 62 anos de idade (média de 50 anos), nove são homens e dez são mulheres. A maioria tem formação de base em sociologia, embora se verifique que alguns estudaram outras áreas (docentes $G, K, L$, $\mathrm{N} 2, \mathrm{O}, \mathrm{Q}){ }^{5}$ Em média, os docentes exercem as suas funções há cerca de 11 anos, havendo porém casos em que se encontram no cargo há apenas um ano, como outros que rondam as três décadas.

Os diretores / coordenadores de curso que foram entrevistados têm entre $37 \mathrm{e}$ 71 anos de idade (média de 54 anos), cinco são homens e oito são mulheres. Nenhum deles tem formação de base em sociologia. Em média, os diretores exercem as suas funções há cerca de cinco anos, havendo porém casos em que se encontram no cargo há apenas um ano, como outros perto das duas décadas.

\section{Presença e avaliação da sociologia no curso}

A maioria dos cursos leciona uma disciplina de sociologia desde a sua criação (cursos A, B, C, D, H, I, K, M, N); nalguns casos, a sociologia foi introduzida com a reestruturação de Bolonha, em 2006 (cursos E, Q).

Questionados sobre os motivos de inclusão da sociologia, os diretores (e alguns docentes que também se pronunciaram sobre o assunto) referem sobretudo a necessidade de estudar as questões centrais dos vários cursos como fenómenos sociais (docente $\mathrm{H} 1$; diretores $\mathrm{A}, \mathrm{H}$ ) e a importância de mobilizar várias áreas do saber na formação dos alunos (docentes E, G; diretores C, E, K, M, Q).

Sociologia em geral, portanto, nós trabalhamos e visamos nos nossos estudantes o desenvolvimento de competências técnicas, científicas, relacionais, entre outras. Mas visando os cuidados ao doente, à família, inseridos na comunidade. Ora a sociologia é imperativa, não é? Portanto, os fenómenos sociais, a inserção social dos nossos utentes, da família... Todas as implicações que a sociedade tem no processo saúde/doença do indivíduo, não é verdade? Portanto é fundamental, é determinante que tenhamos uma unidade curricular que, enfim, aborde essas temáticas de uma forma mais geral ou mais específica. [Diretora A, SBE]

Foi o espírito de Bolonha, digamos. O espírito de Bolonha tinha um pouco a ver com isso, que era as pessoas terem, para além de disciplinas da sua área de formação -

5 Na maior parte das situações, a unidade curricular já existia mas houve necessidade de substituição do docente anterior e, por maior afinidade com a área em questão e opção de se trabalhar com o corpo docente existente na instituição, foram convidados a lecionar a disciplina. 
que neste caso incluía disciplinas de matemática, informática e estatística - , deveriam incluir também disciplinas de áreas mais abrangentes, e que portanto lhes pudessem abrir os horizontes em relação a outras matérias. [Diretora Q, OA]

Nalguns casos é referida a importância da "visão" dos fundadores dos cursos ou da "tradição" multidisciplinar das instituições de ensino superior em que se inserem (diretor e docente D; docente B1 e diretora B; diretora J; docente P). No entanto, nem todos os diretores souberam responder a esta questão (diretores F, L, N).

Tendo sido pedido que fizessem uma avaliação da presença da sociologia no curso, docentes e diretores têm visões semelhantes - embora, mais uma vez, alguns diretores não elaborem muito a sua opinião (diretores $\mathrm{F}, \mathrm{L}, \mathrm{Q}$ ). A perspetiva mais comum é a avaliação positiva, sem reservas ao sentido que faz no curso e na formação dos alunos (diretor e docentes $\mathrm{H}$; diretora e docente $\mathrm{C}$; diretores A, D, E, $\mathrm{N}$; docente $\mathrm{O}$ ), tendo até bastante peso em dois cursos ( $\mathrm{C}$ e N). Outro tipo de asserção muito comum é uma avaliação positiva mas afetada pelo pouco interesse ou resistência dos alunos (docentes D, I, K, L, Q; diretora e docentes B; diretora M).

Faço uma avaliação talvez um bocadinho ambivalente. [...] Tratava-se de uma valência importante que era necessário preservar no curso de forma a que, enfim, os estudantes pudessem ter essa vertente no seu currículo. No que diz respeito aos efeitos práticos disso, quando digo que é ambivalente é porque ao nível da disciplina junto dos estudantes [...] é muito frequente haver vários tipos de, não só de equívocos, mas mais de anticorpos. [Docente B2, SBE]

Acho que a avaliação é positiva. Tem alguns obstáculos. Porque, nesta faculdade, escola, universidade, há uma maior preponderância da parte prática. Têm muito o ensino mais voltado para a prática e eu acho que os próprios alunos já vêm com essa expectativa. E quando surgem cadeiras teóricas ficam com um grande sentido de rejeição, OK? [Docente L, AH]

Porém, independentemente da importância que os entrevistados possam atribuir à inclusão da sociologia no curso, vários deles - quase exclusivamente docentes referem que a sua presença tem vindo a diminuir (por exemplo, os docentes A, B1, $\mathrm{M}, \mathrm{O}$ e $\mathrm{P}$ referem que a sociologia diminuiu no curso após o processo de Bolonha) e/ou receiam que possa vir a ser cortada no futuro, pelo facto de haver vozes contra a sociologia, jogos de poder dentro da instituição ou por ser essa a direção que ultimamente as políticas educativas têm tomado (docentes B1, B2, L, K, N1, N2, O; diretor $\mathrm{E})$.

Quer dizer, a única coisa que eu posso acrescentar de contexto, é que a tendência pelo menos aqui nesta universidade, não sei como é que é nas outras - é para se ir, cada vez mais, empobrecendo o leque de optativas que os alunos têm. [...] Portanto, não me admiraria muito que se nós viermos a falar daqui a cinco anos, que a disciplina entretanto possa ter caído, está a perceber? Mas eu penso que isto acontece aqui, como acontece na maior parte das universidades. E infelizmente tenho a sensação que as 
disciplinas que marginalmente podem chamar os alunos para a área do pensamento, ou do pensamento crítico, são essas que realmente estão a ser cortadas, mais rapidamente cortadas. [Docente $\mathrm{K}, \mathrm{AH}$ ]

Nós temos assistido é ao desaparecimento da sociologia da estrutura curricular dos cursos. [...] quando houve a passagem de bietápico para licenciatura de quatro anos, as unidades curriculares que acabaram por sair foram as ligadas às ciências sociais e humanas, nomeadamente, a sociologia, a psicologia e outras áreas afins. A própria antropologia. [...] Também os próprios sucessivos governos têm valorizado o ensino superior politécnico mais técnico. E tem-se assistido sempre a ter que cortar em unidades curriculares e acabam por ser sempre as nossas. Antigamente, tínhamos aqui uma carga horária significativa e, entretanto, tem vindo a diminuir. [Docente $M$, serviços]

Eu sinto que há muita gente que está incomodada com o peso que nós temos [...]. Acham que nós estamos demasiado envolvidos em tudo o que é cursos e devíamos ser postos no nosso lugar, não é. Sinto isso. Sinto. E, portanto, sempre que apanham uma oportunidade de nos desalojarem, se essa oportunidade surgisse não tenho dúvidas que o fariam. [Docente N2, educação]

Verifica-se também a tendência de substituição por outras ciências sociais, sobretudo pela psicologia (docentes B1, D, M). Por outro lado, é importante que a sociologia não seja redundante face a outras disciplinas (diretor H; docentes H2, N1). Alguns dos entrevistados também chamam a atenção para o facto de, em certos casos, a presença da sociologia não se limitar às disciplinas com esta designação específica (docentes N1, N2).

Questionados sobre se os alunos destes cursos terão alguma vantagem relativamente a alunos de cursos semelhantes, noutras instituições, mas onde a sociologia não é lecionada, a maioria dos entrevistados considera que os cursos da mesma área também oferecem este tipo de disciplinas, pelo que a situação não se aplica. Porém, nas áreas da saúde e bem-estar (diretora e docente $\mathrm{D}$, diretora e docentes $\mathrm{B}$, diretora A), engenharia, manufatura e construção (docentes $\mathrm{O}, \mathrm{P}$ ), artes e humanidades (docente L; diretores $\mathrm{K}, \mathrm{J}$ ) e outras áreas (diretora $\mathrm{Q}$ ), tendencialmente consideram que sim.

Agora, claro que os alunos que saem desta faculdade - os de engenharia - têm um perfil diferente dos outros. Portanto, são alunos que têm uma preparação, em termos de conhecimento, em áreas de ciências sociais, muito maior do que os outros, o que significa que isso tem sido de certo modo explorado pela própria escola, que diz que eles de facto são habilitados não só para os aspetos meramente técnicos, mas para uma visão mais holística dos problemas do desenvolvimento da tecnologia. [Docente P, EMC]

[...] eu acho que tudo o que nós lhes possamos oferecer em termos de outras áreas que não só aquela da qual somos peritos, digamos, entre aspas, poderá ser-lhes útil, e eu 
acho que a sociologia é uma dessas áreas. Acho que realmente constitui uma mais-valia. Aliás, eu acho que outros cursos [...] que estejam integrados noutras faculdades que não têm valências tão distintas como a nossa, não conseguem nunca ser tão ricos para eles como é o nosso aqui. [Diretora $\mathrm{Q}, \mathrm{OA}$ ]

\section{Considerações sobre o ensino da disciplina}

Os docentes foram questionados sobre se sentiam alguma dificuldade em particular no ensino desta disciplina aos alunos, nomeadamente pelo facto de muitos virem, provavelmente, de áreas do secundário onde não tiveram contacto com a sociologia - o que, por si só, é visto como uma dificuldade: tratando-se de uma área algo distante dos seus interesses, os alunos costumam manifestar alguma resistência inicial (docentes B1, D, E, H2, M, Q).

Além desta situação, a principal dificuldade referida pelos docentes advém da conjugação de uma série de limitações intelectuais que são apontadas aos alunos e com as quais se defrontam: fracos hábitos de leitura e escrita (redundando em dificuldades de interpretação e desenvolvimento de raciocínios); dificuldade em trabalhar em grupo e em discutir ideias; falta de cultura geral; fortes componentes de passividade e imaturidade (docentes A, B2, C, I, K, L, N2, O).

As dinâmicas vão mudando, porque as gerações vão sendo muito diferentes... as minhas aulas agora não têm nada que ver com as minhas aulas de há dez anos atrás, ou há 15 anos atrás, [...] agora eu tenho alunos que se sentam, querem ouvir, que ficam muito perturbados se formos para além desta dinâmica um pouco escolástica... tenho cada vez mais dificuldade em ter debates em sala se não forem pré-programados, e se forem pré-programados não funcionam porque para serem pré-programados tinham de ser preparados e há alguma dificuldade em ler, em fazer essas coisas normais da vida de um estudante... [Docente I, CSJI]

Sinto dificuldade inerente ao facto de estarem muito pouco habituados a ler, não dominarem a bibliografia básica, e portanto há ali um primeiro momento que é estar a dar conceitos a um nível muitíssimo básico. [Docente $\mathrm{K}, \mathrm{AH}$ ]

Este tipo de crítica, além de bastante alargado, surge muitas vezes espontaneamente, sem que tenha sido colocada nenhuma questão nesse sentido, e também encontramos diretores que se pronunciam a este respeito (diretores $\mathrm{B}, \mathrm{K}$ ).

O que também causa alguma dificuldade aos docentes é o facto de a sociologia ser muitas vezes vista como uma "ciência da mesa de café" (docentes A, C, H1, $\mathrm{M}, \mathrm{N} 3$ ).

Sabe qual é o problema da sociologia? É facilmente uma ciência de mesa de café. Qualquer pessoa sabe falar sobre o social, sobre o que é que é importante, o que nãoé, o que levou a pessoa a fazer aquilo, o que é que não levou, está a perceber? E, portanto, os meus alunos não são... não são isentos dessa lógica da sociologia da mesa de café. E eu 
escrevo-lhes muitas vezes nas anotações dos testes: "não estamos à mesa do café ou à mesa do bar a discutir estes conceitos, isto é senso comum". [Docente C, SBE]

Quando nós vamos para sociologia, nós vamos porque gostamos ou porque temos predisposição para. E portanto, nós vamos tirar um curso de sociologia e, pronto, é aquilo que a gente gosta e aquilo que a gente quer. E estamos virados para aí. Nestes cursos, os alunos não estão virados para aí. Estão muito longe do social. O social faz parte daquela coisa normal, até se pode falar num café, para quê se explicar sociologia? Há a sociologia do senso comum. A gente explica tudo. Para quê? Não há muitas diferenças, não é? [Docente H1, CSJI]

Em parte derivando de críticas anteriores, alguns docentes referem também a dificuldade em fazê-los pensar, raciocinar, romper com o senso comum (docentes A, C).

Porém, também houve docentes (sobretudo nas áreas da educação e engenharia) que indicaram não sentir qualquer dificuldade no ensino da disciplina (docentes G, N1, N3, O, P).

Vários entrevistados referem que a disciplina é mais bem recebida (e compreendida) pelos estudantes em regime pós-laboral ${ }^{6}$ ou ao nível de mestrados e doutoramentos, pois a idade e experiência profissional mais avançadas incutem uma maior maturidade aos alunos que lhes dá uma perspetiva diferente, pelo que estes alunos compreendem melhor a "utilidade" da disciplina e são também mais participativos nas aulas (diretor e docente E, diretor F, docente B1). Contrariando esta perspetiva, a docente $C$ pensa que os alunos mais velhos têm mais dificuldade em desmontar as ideias de senso comum.

\section{Expectativas de competências adquiridas e contributo para a inserção profissional e futuras funções dos alunos}

As principais competências que os docentes esperam que os seus alunos adquiram são - além da apreensão dos conceitos-chave da disciplina, naturalmente - o desenvolvimento da capacidade crítica, reflexiva, e o rompimento com o senso comum (docentes B1, B2, C, D, E, H1, I, L, M, N1, N2, N3).

Não sei se eles desenvolvem ou não, mas desejaria que eles desenvolvessem competências sobretudo de análise crítica, de reflexão crítica. Mais do que qualquer outra coisa. Não desejaria nem esperaria que se transformassem em sociólogos, ou que desenvolvessem um ponto de vista próximo do dos sociólogos, não me interessa. Mas que aprendessem a ler a realidade e, sobretudo, a criticar; a olhar com um olhar mais crítico, portanto, menos passivo, a realidade e as coisas que lhes são ditas. [Docente I, CSJI]

6 Os cursos E, F, G e N têm oferta pós-laboral. 
O que é que a sociologia dá? Dá, deve dar em primeiro lugar capacidade de análise, de reflexividade, de sensibilidade social, de compreensão, de explicitação, uma capacidade discursiva, de argumentação sociológica, não é. Digamos, com força, poderosa, não é, capacidade de interpretar, convencer, participar nos debates. Capacidade de fundamentar e de identificar, digamos, os fatores isolados ou inter-relacionados, a tal constelação de fatores que muitas vezes está por detrás dos fenómenos, de dinâmicas, de comportamentos individuais ou coletivos, não é, isso é muito importante. [Docente N3, educação]

São também referidas a aquisição de uma perspetiva das áreas de estudo enquanto fenómenos sociais (docentes B1, B2, C, D, G, H2, O, Q), o desenvolvimento de capacidades de escrita e de leitura, de trabalho em grupo e de exposição oral (docentes D, K, N3, P). Menos comuns, mas também indicadas, são as competências para a futura atividade profissional (docentes A, B1).

[...] há também aqui um conjunto de lógicas que está a mudar e portanto é dizer: "Olhem, compreender isto é ter a possibilidade de saber analisar criticamente os fenómenos que vão caracterizar a vossa prática e é, em termos profissionais, ser um técnico preparado para lidar com a diversidade de situações que, sem surpresa, poderão vir a acontecer". [Docente B1, SBE]

Se eles saírem daqui com a noção de que a dimensão social é tão ou mais relevante que a dimensão técnica, e que as coisas não estão desligadas, isso para mim era ouro sobre azul. Quando eles pensam em políticas, quando pensam em técnicas, quando pensam em tecnologias, nada dessas coisas são socialmente neutras, logo estão articuladas. [Docente O, EMC]

É também comum o reparo de que nesses cursos não se estão a formar sociólogos, pelo que as expectativas em termos de competências adquiridas ao nível da sociologia são bastante moderadas (docente I, diretor e docentes $\mathrm{H}$ ). E a própria noção de "competências" é muitas vezes questionada pelos entrevistados.

Colocando a mesma questão aos diretores, vários não sabem como responder (diretores F, J, L, Q). No entanto, aqueles que oferecem a sua opinião referem sobretudo o desenvolvimento da capacidade crítica e analítica dos fenómenos (diretores $\mathrm{B}, \mathrm{C}, \mathrm{H}, \mathrm{K}, \mathrm{M}, \mathrm{N}$ ), assim como o desenvolvimento de competências inter-relacionais (diretores C, D, E) e de utilidade para o futuro profissional (diretoras A, D) - o que não deixa de ser uma visão um pouco diferente da dos docentes.

Obviamente, depois por outra vertente, também a relação entre profissionais e entre toda a equipa de profissionais de saúde e os seus pares. Também desenvolver competências nesta área de estar com os outros. E de estar em comunidade, saber trabalhar em equipa e saber respeitar o outro. [Diretora D, SBE]

Eu espero que eles consigam perceber que para se inserirem no mundo do trabalho têm que ter algumas competências... vamos chamar-lhes inter-relacionais, enfim, 
competências de inter-relação com os outros e de adaptação à própria cultura organizacional, que podem ser adquiridas, sensibilizando-os para os temas, lecionando aulas essencialmente práticas, com casos práticos, com recurso a vídeos, com recurso a filmes, que lhes permitam perceber melhor como é o mundo do trabalho [...]. [Diretor E, GAD]

Entre os docentes, as opiniões dividem-se sobre se as disciplinas de sociologia poderão ter algum contributo para a inserção profissional dos alunos. Mais comummente, acreditam que poderá ter importância, mesmo que de uma forma indireta, através do alargamento de horizontes (docentes D, E, K, L, M, N2, O, P). Outros são otimistas mas advertem que depende do empregador (docentes B1, B2, H1, H2, N3).

Portanto não é um contributo direto, penso eu, para a inserção; são contributos mais de pré-empregabilidade, quase. De apoio à empregabilidade. Não vejo que isto lhes seja diretamente útil eles irem para lá dizerem que tiveram sociologia das organizações, não será bem por aí. [Docente E, GAD]

Quer dizer, há duas perspetivas. Há a nossa e poderá haver a da entidade empregadora que poderá olhar para o currículo e achar interessante que o aluno tenha tido uma formação naquela área e que seria pertinente. Mas também depende de quem é o empregador e de qual é a sua formação. Para nós, enquanto formadores, enquanto instituição, para nós é importante que os alunos saiam com este olhar... com esta capacidade de olhar para a sociedade e vê-la de uma forma mais global. [Docente H1, CSJI]

Mas normalmente aqueles [ex-alunos] que eu conheço e que têm dado esse feedback, normalmente é muito positivo, porque dizem justamente que nas empresas, quando eles querem ir trabalhar, o que lhes pedem, é claro que tenham essa formação de engenharia em geral, mas o facto de ter uma formação em ciências sociais é o que lhes permite ser diferentes de outros e serem capazes de colaborar com departamentos ou com áreas das empresas que usualmente os engenheiros não têm capacidade. [Docente P, EMC]

Porém, há também docentes que não acreditam que a sociologia poderá ter alguma importância na inserção profissional dos alunos (docentes C, G, N1).

Já os diretores manifestam-se pouco, geralmente não têm uma ideia concreta sobre o assunto (diretores A, B, F, J, N), ou são mais pessimistas (diretores C, E, H, L, M, Q). Poucos manifestam uma opinião cautelosamente otimista (diretores $\mathrm{D}, \mathrm{K})$.

Quanto ao possível contributo da sociologia para as funções profissionais que os alunos poderão vir a desempenhar no futuro, na maior parte, docentes e diretores acreditam que a disciplina tem importância, mesmo que indiretamente de tal forma que é mais simples enunciar aqueles que não têm uma opinião formada ou consideram que não existe nenhum contributo significativo (diretores $F, L$, $\mathrm{N}$, docente N1). 
Acho que sim, na compreensão do outro. A compreensão de por que é que eu me comporto daquela forma [...]. Por outro lado, também a sociologia tem a componente de, muitas vezes nós, profissionais de saúde, não conseguimos viver isolados. Vivemos sempre em equipa, sempre em inter-relação; não há outra forma. Eu costumo dizer: em saúde são equipas multidisciplinares, cada vez maiores. [...] E portanto tudo isso, eu acho que o facto de se eles encarassem a sociologia desta forma, eu acho que era mais fácil a sua entrada no mundo de trabalho, o seu estágio, etc., toda essa relação era mais fácil. [Diretora B, SBE]

Porém, alguns docentes têm uma posição muito particular, em que rejeitam a avaliação utilitarista da disciplina (docentes I, N2).

Mas se a disciplina tem ou não tem contributo futuro, para o futuro profissional, interessa-me pouco. Eu não estabeleço nenhuma relação utilitária entre as disciplinas que são lecionadas na universidade, num curso universitário, e depois o futuro profissional. [...] Quando eles manifestam esse tipo de preocupação eu procuro desconstruir isso e faço-lhes o discurso que estou a fazer aqui, e dizer-lhes que se eles quisessem de facto aprender aquilo que vão pôr em prática, iam para um curso de formação profissional, não vinham para aqui. Aqui, vêm desenvolver-se como pessoas, vêm aprender a pensar, aprender a olhar a realidade e se eu puder contribuir para isso, por pouco que seja, já me sinto feliz. [Docente I, CSJI]

Há uma ideia ainda muito utilitarista da educação e mesmo os próprios colegas que trabalham essas questões tentam, no fundo, dar-lhes o que chamam as competências para trabalhar, as competências para se adequarem ao mercado de trabalho e eu penso que devemos fazer ao contrário. Eu costumo dizer nas aulas até a propósito de uma pergunta que eles me fizeram: “Para que é que isso serve professor? Não serve para nada, aquilo que eu vos digo não tem nenhum tipo de utilidade e portanto não serve para nada, não é para levar a sério." E acho que a educação é isso mesmo, não deve servir para nada, não tem que ter utilidade. A utilidade é uma outra questão e, portanto, se quiserem refletir sobre a vida, sobre o mundo, a essa reflexão estamos abertos. [Docente N2, educação]

Também houve referências ao facto que muitas vezes os ex-alunos, depois de entrarem no mercado de trabalho, transmitem um feedback positivo dos ensinamentos que receberam nestas aulas, pois frequentemente só mais tarde é que conseguem verdadeiramente entender a sua pertinência (diretora B e docente B2, diretora e docente $\mathrm{D}$, docentes $\mathrm{M}, \mathrm{P}$ ).

\section{Perspetivas sobre os aspetos mais e menos valorizados pelos alunos}

Apesar de se tratar de disciplinas muito variadas dentro da área científica da sociologia, os docentes têm uma visão semelhante sobre este assunto: praticamente todos referem que o aspeto mais valorizado pelos alunos são as próprias temáticas 
lecionadas, sobretudo quando relacionadas com os seus interesses e ilustradas com exemplos ou trabalhos práticos. Alguns docentes referem também como aspeto muito valorizado a utilização de métodos pedagógicos que tornem as aulas mais dinâmicas, nomeadamente o recurso a vídeos e outros meios audiovisuais (docentes $Q, N 1$ ). Por vezes, o facto de ser uma unidade curricular diferente também pode ser interessante para os alunos (docentes D, M).

Quanto aos aspetos menos valorizados pelos alunos na perspetiva dos docentes, surge de forma bastante alargada a referência ao caráter teórico da disciplina (docentes B2, C, D, G, H1, H2, I, K, L, M, N1, N2). Aqui, o sentido de "teórico" pode referir-se a vários aspetos, como por exemplo as aulas serem muito expositivas, os conceitos estudados serem muito abstratos ou, sobretudo, existir um corpo de autores clássicos cujas perspetivas teóricas enquadram a disciplina e devem ser apreendidas.

Tudo o que for explicações, conceitos, noções mais abstratas, mais difíceis de chegar, de certa maneira, ao concreto do quotidiano, do dia a dia, para eles é o mais desvalorizado. Se for alguma coisa que não compreendam, não tem valor, percebe? [...] Se eu começar pelo abstrato eu sei que perco a turma em cinco minutos. [Docente C, SBE]

Primeiro, eles têm expectativas muito práticas. $O$ nosso conceito central é o conceito de sociedade, que é um conceito altamente abstrato, não é? Portanto a cadeira é uma cadeira estranha para eles, exatamente por causa deste nível teorético. [...] Um outro problema é a estrutura normativa. [...] Portanto uma estrutura normativa muito rígida no ensino nas áreas da saúde confronta-se muito com a abordagem pluriparadigmática que eu dou. [Docente D, SBE]

A sociologia é uma ciência que, ao contrário de outras, os nossos teóricos são algo complexos. E é difícil falarmos, por exemplo, de classes sociais, sem referirmos os clássicos e fazer aquela evolução. E isso, para este tipo de alunos, para este público, é, utilizando um conceito que eles utilizam muitas vezes, secante. Portanto eles precisam e é preciso articular rapidamente os conceitos, se calhar, com um artigo que já tenha dados empíricos. [Docente $\mathrm{M}$, serviços]

A questão da teoria é sobretudo importante quando os cursos são lecionados em institutos politécnicos; aqui sente-se alguma diferença face ao ensino universitário e os entrevistados fazem constantemente essa ressalva. Existe alguma dualidade na tentativa de equilibrar a visão mais prática dos cursos com o contributo que as disciplinas mais teóricas também dão.

E isso nota-se no curso do seguinte modo: ele é politécnico, OK? Sem dúvida. E portanto procura dirigir os alunos para campos um pouco mais específicos de aplicação. Mas [...] em determinadas áreas das humanidades e das ciências sociais, não pode deixar de lhes dar uma boa formação teórica. Mesmo sendo um curso politécnico. Ou seja, não é um curso só de maquinetas e de aparelhómetros, OK? É um curso em que, pelo menos, na fase inicial e intermédia, a formação teórica é absolutamente essencial. [Diretor H, CSJI] 
E compreende-se, porque os próprios alunos que nós temos estão a fugir da teoria, eles procuram cursos mais práticos mesmo a todos os níveis. É um discurso frequente que "se nós quiséssemos refletir teorias, teorizar, trabalhar teoria, se calhar, não estávamos aqui, estávamos noutro sítio". [Docente M, serviços]

Outro aspeto menos valorizado - e que acaba por estar relacionado com o anterior - é a necessidade de fazer leituras, mais ou menos extensas, e que podem ter ainda a dificuldade acrescida de não serem em português, o que provoca algum desânimo nos alunos (docentes B1, N1, N2, Q).

Em consequência do caráter mais expositivo e teórico da sociologia, e pela particularidade de se tratar de uma área científica muitas vezes distante da área central do curso, surge com frequência a necessidade de se proceder a uma adaptação pedagógica (docentes D, H1, N1, N3, P). Em resultado, os docentes tentam recorrer a muitos exemplos práticos e à simplificação do ensino dos conceitos mais abstratos.

Mas é realmente esta a luta que nós temos: equilibrar entre a teoria e a dimensão prática sem que uma descure a outra, obviamente, nem o rigor científico, mas, ao mesmo tempo, não perder o público. Porque senão a gente perde o público e eu acho que esse também não é um bom trabalho que a gente faz para a sociologia. [Docente H1, CSJI]

Quer dizer, se eu desse aulas só a falar em teorias sociológicas, os alunos acabavam por adormecer e aborreciam-se com isso. Apesar de tudo, a estratégia pedagógica não pode ser essa, não é dar sociologia como se os alunos fossem estudantes de sociologia. Eles estão ali para aprender conceitos básicos, mas eles podem ser dados de uma maneira diferente e acabamos por chegar a atingir os objetivos que são necessários [...]. [Docente P, EMC]

No entanto, esta "simplificação" também deve ser encarada com cautela, pois pode ter efeitos secundários indesejados, como a perda de rigor científico.

Às vezes lembro-me quando o Sedas Nunes dizia, e o Durkheim também, muitas vezes se chegou a falar nisso, "o que a sociologia pode perder em popularidade, ganhá-lo-á em dignidade”. Para nós, isso é importante. Ou seja, não é dizer que somos herméticos, até porque fazemos um esforço para não ser; mas evitamos fazer o populismo da sociologia, a propaganda da sociologia. [Docente B1, SBE]

Eu acho que a única diferença e, por isso, é que temos alguma dificuldade, é que a sociologia na forma como nós a lecionamos, principalmente em cursos com componentes significativamente práticos, é que temos que aligeirar o processo das teorias. E depois, a partir de certa altura, acabamos por transmitir uma imagem de uma sociologia, mas de uma sociologia - isso é uma análise que eu faço - de uma sociologia algo superficial. De uma sociologia que se confunde com... com algo pouco científico, com algo pouco estruturado, com algo que não tem bases teóricas fortes. [Docente $M$, serviços] 
Eu acho que estamos a simplificar demasiado o exercício da docência e da... em cada uma das unidades, estamos a transformar isto quase num curso profissional de nível superior. E isso pode ser problemático. [Docente N2, educação]

\section{Reflexões finais}

A presença da sociologia nos cursos em foco é, no geral, bastante antiga e consolidada. Em vários casos, a sua inclusão deveu-se à "visão" dos fundadores dos cursos ou de uma determinada tradição das instituições, que valorizam a vertente multidisciplinar do ensino superior. A presença da disciplina é assim vista como sendo importante no âmbito dos cursos, ao permitir abordar os temas centrais lecionados como fenómenos sociais e desenvolver o sentido crítico nos alunos.

No entanto, na perspetiva dos entrevistados, a presença da sociologia tem vindo a diminuir, ou é expectável que venha a ser cortada no futuro, em grande parte dos cursos, possivelmente em favor da substituição por outras ciências sociais - esta é uma preocupação manifestada quase exclusivamente pelos docentes. Sabendo que entre os anos letivos de 1989/1990 e de 2013/2014 houve uma expansão considerável da oferta de disciplinas de sociologia em cursos de outras áreas de formação no ensino superior português (Egreja, 2014), novas interrogações surgem: será que a presença da sociologia atingiu o seu auge antes da implementação do Processo de Bolonha, havendo então lugar a um corte significativo desta oferta? E após a sua implementação, a tendência tem sido realmente de decréscimo? Para poder determinar até que ponto a opinião dos entrevistados corresponde, de facto, à realidade, novas análises terão de ser levadas a cabo.

Os docentes referem que as dificuldades que normalmente surgem no ensino da disciplina são a falta de hábitos de escrita e leitura dos alunos, o seu baixo nível de cultura geral e imaturidade, acentuados de ano para ano - na verdade, estas são críticas apontadas várias vezes de forma espontânea, tanto pelos docentes como pelos diretores de curso, transversalmente aos vários cursos e tipos de instituições de ensino. Diretamente relacionados com a área da sociologia, surgem alguns reparos ao facto de esta ser muitas vezes vista como uma "ciência da mesa de café" e que, como tal, traz maiores dificuldades a quem não tenha interesse pela área.

Questionados sobre as competências que gostariam que os alunos adquirissem, docentes e diretores destacam o desenvolvimento da capacidade crítica e reflexiva; o rompimento com o senso comum; a aquisição de uma perspetiva das áreas de estudo enquanto fenómenos sociais; o desenvolvimento de capacidades de escrita e de leitura, de trabalho em grupo e de exposição oral; e, menos frequentemente, o desenvolvimento de competências inter-relacionais - se bem que o próprio conceito de "competências" seja por vezes desvalorizado.

Os entrevistados foram ainda confrontados com o possível contributo da disciplina para a inserção profissional e futuras funções a desempenhar nesse contexto. De um modo geral, a opinião é bastante indicadora de um contributo favorável, ainda que indireto (e, a espaços, até questionando se a pertinência da sociologia deve ser colocada nesse tipo de assunções utilitaristas). 
Por fim, apesar de se tratar de disciplinas muito variadas dentro da área científica da sociologia, os diferentes docentes têm uma visão semelhante sobre qual será o aspeto mais valorizado pelos alunos: as próprias temáticas lecionadas, sobretudo quando relacionadas com os seus interesses e ilustradas com exemplos ou trabalhos práticos. Alguns docentes referem também como aspeto muito valorizado a utilização de métodos pedagógicos que tornem as aulas mais dinâmicas, nomeadamente o recurso a vídeos e outros meios audiovisuais. Quanto aos aspetos menos valorizados pelos alunos na perspetiva dos docentes, surge de forma bastante alargada a referência ao caráter teórico da disciplina; aqui, o sentido de "teórico" pode referir-se a vários aspetos, como por exemplo as aulas serem muito expositivas, os conceitos estudados serem muito abstratos ou, sobretudo, existir um corpo de autores clássicos cujas perspetivas teóricas enquadram a disciplina e devem ser apreendidas. Outro aspeto menos valorizado - e que acaba por estar relacionado com o anterior - é a necessidade de fazer leituras, mais ou menos extensas, e que podem ter ainda a dificuldade acrescida de não serem em português.

Comparando as opiniões de diretores e docentes no mesmo curso, vemos na verdade que, na maior parte dos casos, se encontram em sintonia - mas os casos em que isso não acontece são bastante reveladores de alguma tensão interna. De resto, podemos concluir que nesta amostra de entrevistados, os docentes constituem um grupo mais homogéneo do que os diretores; nestes últimos, encontramos indivíduos muito interessados e envolvidos na organização dos cursos, e que atribuem importância à sociologia nos mesmos, como outros que mostraram grande desinteresse e/ou desconhecimento do funcionamento da disciplina. De realçar que não foi possível entrevistar o par docente / diretor em todos os cursos, e essas recusas também são indicadoras, por si só, do desinteresse que este tema parece ter junto de algumas pessoas, sobretudo ao nível dos cargos de coordenação.

Não se encontram diferenças relevantes nas respostas dadas pelos entrevistados consoante o subsistema de ensino em que se inserem, com exceção da referência ao caráter "teórico" da disciplina que parece ser mais problemático nos institutos politécnicos, pela sua natureza intrínseca. Também a área científica não parece produzir grandes diferenças de perspetivas. É porém de referir que mesmo em áreas das ciências naturais ou tecnológicas, a sociologia é relativamente bem recebida, enquanto em áreas que se poderiam supor mais próximas - nas artes e humanidades ou nas ciências sociais - se encontram casos de alguma desvalorização do seu interesse.

Procurou-se com o presente artigo contribuir para o conhecimento sobre a presença da sociologia em cursos de outras áreas, no ensino superior português, através da análise das representações dos atores fundamentais desta formação, os professores e os diretores dos cursos. No entanto, esta é apenas uma de várias vertentes de investigação prosseguidas com o objetivo de aprofundar o conhecimento sobre esta realidade. 


\section{Referências bibliográficas}

Almeida, A. N. de (2004), “Ensino e investigação na sociologia: convergências e divergências múltiplas", em C. M. Gonçalves, E. Rodrigues e N. Azevedo (orgs.), Sociologia no Ensino Superior. Conteúdos, Práticas Pedagógicas e Investigação - Actas do Encontro Realizado nos Dias 6 e 7 de Dezembro de 2002 na FLUP, Porto, Departamento de Sociologia da FLUP, pp. 18-32.

Almeida, J. F. de (1992), “Trabalhar em Sociologia, ensinar Sociologia”, Sociologia, Problemas e Práticas, 12, pp. 187-199.

Cortesão, L. (1992), “Algumas ambições e limites da formação de professores: papel da Análise Social da Educação", em A. J. Esteves e S. Stoer (orgs.), A Sociologia na Escola - Professores, Educação e Desenvolvimento, Porto, Edições Afrontamento, pp. 231-246.

Costa, A. (1996), "Sobre o campo da sociologia e as práticas sociológicas em Portugal", Sociologia, Problemas e Práticas, 20, pp. 171-178.

Costa, A. (2004), “Será a sociologia profissionalizável?”, em C. M. Gonçalves, E. Rodrigues e N. Azevedo (orgs.), Sociologia no Ensino Superior. Conteúdos, Práticas Pedagógicas e Investigação - Actas do Encontro Realizado nos Dias 6 e 7 de Dezembro de 2002 na FLUP, Porto, Departamento de Sociologia da FLUP, pp. 35-60.

Egreja, C. (2014), "A Sociologia como disciplina em cursos de outras áreas científicas no ensino superior português", CIES e-Working Paper, 188/2014.

Esteves, A. J. (2004), “Métodos, práticas pedagógicas e públicos da Sociologia: um ponto de vista situado", em C. M. Gonçalves, E. Rodrigues e N. Azevedo, (orgs.), Sociologia no Ensino Superior. Conteúdos, Práticas Pedagógicas e Investigação - Actas do Encontro Realizado nos Dias 6 e 7 de Dezembro de 2002 na FLUP, Porto, Departamento de Sociologia da FLUP, pp. 61-77.

Esteves, A. J., e S. Stoer (orgs.) (1992), A Sociologia na Escola - Professores, Educação e Desenvolvimento, Porto, Edições Afrontamento.

Machado, F. L. (1993), “O ensino da sociologia: entre a ciência e a profissão”, Caderno de Ciências Sociais, 12/13, pp. 81-105.

Machado, F. L. (2004), “Quatro princípios para o ensino da sociologia”, em C. M. Gonçalves, E. Rodrigues e N. Azevedo (orgs.), Sociologia no Ensino Superior. Conteúdos, Práticas Pedagógicas e Investigação - Actas do Encontro Realizado nos Dias 6 e 7 de Dezembro de 2002 na FLUP, Porto, Departamento de Sociologia da FLUP, pp. 115-122.

Machado, F. L. (2009), “Meio século de investigação sociológica em Portugal - uma interpretação empiricamente ilustrada", Sociologia, 19, Porto, Departamento de Sociologia da FLUP, pp. 283-343.

Nunes, A. S. (1963), "Problemas da Sociologia em Portugal”, Análise Social, I (3), pp. 459-464.

Nunes, A. S. (1988), “Histórias, uma história e a História - sobre a origem das modernas ciências sociais em Portugal", Análise Social, XXIV (100), pp. 11-55.

Pinto, J. M. (1994), Propostas para o Ensino das Ciências Sociais, Porto, Edições Afrontamento.

Pinto, J. M. (2004), “Formação, tendências recentes e perspectivas de desenvolvimento da sociologia em Portugal", Sociologia, Problemas e Práticas, 46, pp. 11-31. 
Quivy, R., e L. V. Campenhoudt (1998), Manual de Investigação em Ciências Sociais, Lisboa, Gradiva.

Resende, J., e M. M. Vieira (1993), “A sociologia e o ensino superior em Portugal: um levantamento e algumas interrogações", Caderno de Ciências Sociais, 12/13, pp. 53-79.

Sebastião, J. (2004), "Modelos de ensino e tendências de mudança no ensino superior", em C. M. Gonçalves, E. Rodrigues e N. Azevedo (orgs.), Sociologia no Ensino Superior. Conteúdos, Práticas Pedagógicas e Investigação - Actas do Encontro Realizado nos Dias 6 e 7 de Dezembro de 2002 na FLUP, Porto, Departamento de Sociologia da FLUP, pp. 122-134.

Vieira, M. M. (2004), “Converter incrédulos: a Sociologia na cidade das Ciências Duras", em C. M. Gonçalves, E. Rodrigues e N. Azevedo (orgs.), Sociologia no Ensino Superior. Conteúdos, Práticas Pedagógicas e Investigação - Actas do Encontro Realizado nos Dias 6 e 7 de Dezembro de 2002 na FLUP, Porto, Departamento de Sociologia da FLUP, pp. 137-156.

Catarina Egreja. Bolseira de doutoramento FCT no Centro de Investigação e Estudos de Sociologia (CIES), ISCTE - Instituto Universitário de Lisboa, Av. das Forças Armadas, 1649-026 Lisboa, Portugal. E-mail: catarina.egreja@sapo.pt

Receção: 07-10-2015 Aprovação: 09-12-2015 
